\title{
Corrosion Behavior of Welded Joint of Q690 with CMT Twin
}

\author{
Peng Liu $\mathbb{D},{ }^{1,2}$ Shanguo Han, ${ }^{2}$ Yaoyong Yi $\mathbb{D}^{2},{ }^{2}$ and Cuixia Yan $\mathbb{D}^{1}$ \\ ${ }^{1}$ Faculty of Materials Science and Engineering, Kunming University of Science and Technology, 68 Wenchang Road, Kunming, \\ Yunnan 650093, China \\ ${ }^{2}$ Guangdong Welding Institute (China-Ukraine E. O. Paton Institute of Welding), Guangdong Key Laboratory of Modern \\ Welding Technology, 363 Changxing Road, Guangzhou, Guangdong 510650, China \\ Correspondence should be addressed to Yaoyong Yi; yiyaoyong@hotmail.com and Cuixia Yan; cuixiayan09@gmail.com
}

Received 4 January 2018; Revised 18 March 2018; Accepted 11 April 2018; Published 4 July 2018

Academic Editor: Sergey Konovalov

Copyright (c) 2018 Peng Liu et al. This is an open access article distributed under the Creative Commons Attribution License, which permits unrestricted use, distribution, and reproduction in any medium, provided the original work is properly cited.

\begin{abstract}
Low alloy steel of Q690 was welded with the method of CMT Twin. The corrosion behavior of welded joint had been investigated using scanning vibrating electrode technique (SVET) in 3.5\% NaCl solution. The research results showed that the appearance of the troostite increased the hardness of the heat affected zone. Furthermore, the corrosion products of different microstructure were identical, and the white products $\left(\mathrm{Fe}(\mathrm{OH})_{2}\right)$ of welded joint turned into products of rufous $\left(\mathrm{Fe}(\mathrm{OH})_{3}\right)$. The quantitative information provided by SVET was discussed, and the corrosion degree was measured by some parameters. In comparison with other areas, the corrosion rates of the overheated zone and the base metal were higher. Then, the corrosion resistance of the weld zone with CMT Twin was greatly improved, when compared with that of the base metal. Therefore, Ni has significant influence on corrosion resistance of weld zone. In summary, it can be discovered that the corrosion rates of various zones were related to the welding heat input.
\end{abstract}

\section{Introduction}

Q690 steel is known as a typical low carbon bainite steel with excellent mechanical properties, and it is widely used in offshore engineering industry $[1,2]$. However, the complex chloride environment tends to be invalidated ahead of lifetime in welded parts, so it is significant to study the corrosion behavior of welded parts $[3,4]$. Furthermore, the chloride environment contains more inorganic salts (such as $\mathrm{NaCl}$ and $\mathrm{MgCl}_{2}$ ) [5], and $\mathrm{Cl}^{-}$is the most important corrosive ion. Subsequently, $\mathrm{Cl}^{-}$is able to destroy the protective effect of the corrosion scales, and it significantly increases the activity of the matrix. So $\mathrm{Cl}^{-}$can accelerate the corrosion rate, and eventually lifetime of the welded joint will be reduced. Owing to the difference of microstructure in the welded joint, the corrosion situation is different. Various traditional corrosion detection methods $[6,7]$ obtain the corrosion condition of the whole electrode only and cannot get the corrosion behavior of the microregions. On microstructure and grain size of the welded joint, the electrochemical method of microregion has peculiar advantages over the classical electrochemical method.
Scanning vibrating electrode technique (SVET) $[8,9]$ is to study the corrosion resistance of samples by detecting the local corrosion potential (current) information of samples without touching the surface of the sample. However, welding defects can affect the electric potential of SVET, thus affecting test results $[10,11]$. Therefore, SVET has been widely used in the research of various types of corrosion, such as pitting, intergranular corrosion, and stress corrosion $[12,13]$.

In previous researches the corrosion behavior of welded joint was studied with SVET. Wang et al. studied the corrosion behavior of HAZ in acidic soil solution with SVET [14]. The results demonstrated that microstructure of granular bainite mixed with ferrite was with the highest charge transfer resistance and the most positive current density value. Acicular ferrite of base metal displayed the lowest charge transfer resistance and the most negative current density. Liu et al. studied the corrosion properties of welded joints with different heat input in high strength low alloy steel [15]. Fuertes et al. used SVET to investigate oxide dissolution and initiation and propagation of corrosion on the welded zone [16]. Luo et al. used SVET to study stress corrosion cracking in heat affected zone [17]. The formation and development 
TABLE 1: The chemical compositions of the tested steel (Q690) and ER 110S-G (wt\%).

\begin{tabular}{|c|c|c|c|c|c|c|c|c|c|c|}
\hline materials & $C$ & $\mathrm{Si}$ & $M n$ & $P$ & $S$ & $V$ & $T i$ & $\mathrm{Cr}$ & $\mathrm{Ni}$ & $\mathrm{Cu}$ \\
\hline Q690 & $\leq 0.18$ & $\leq 0.50$ & $\leq 1.70$ & $\leq 0.025$ & $\leq 0.02$ & $\leq 0.15$ & $\leq 0.2$ & $\leq 0.3$ & $\leq 0.50$ & $\leq 0.30$ \\
\hline ER $110 S-G$ & $\leq 0.1$ & $0.4-0.8$ & $1.5-1.8$ & $\leq 0.02$ & $\leq 0.02$ & - & - & - & $1.3-1.6$ & $0.2-0.4$ \\
\hline
\end{tabular}

of stress corrosion cracking were explained. Ma et al. used SVET to investigate the localized corrosion behaviors of the welded joint [18]. They discovered that there were the maximum microhardness and the densest microstructure in the welded zone compared with the other zones. And the welded zone presented the lowest current density due to the presence of iron oxides and the densest microstructure, thus showing the excellent corrosion resistance. Indeed, the SVET results reveal that the corrosion rates of welded specimens are associated with the welding heat input and corrosion products.

The above studies indicate that the various microstructure of the welded joint is an important parameter of affecting corrosion resistance. Adopting local electrochemical measurement techniques for characterizing the localized corrosion of welded joint can better reveal the corrosion mechanism, and the corrosion behavior of welded joint with different microstructure is clearly evaluated. It is relatively rare to study the corrosion resistance of welded joints with SVET technology in chloride environment. Therefore, it is significant for the research of Q690 in 3.5\% NaCl solution.

In this work, a SVET method provided further valuable information on different microstructure of the welded joints and evaluated the corrosion resistance of the welded joint. Combined with the microstructure and hardness analysis, the corrosion behavior of Q690 with CMT Twin in 3.5\% $\mathrm{NaCl}$ solution was carried out.

\section{Experimental}

2.1. Materials. The low alloy steel of Q690 was welded with CMT Twin, and the dimension of groove was shown in Figure 1. In this work, the welding wire (type: OK AristoRod 69/ER110S-G, produced by ESAB company) of $1.2 \mathrm{~mm}$ in diameter was utilized as the filling material in welding groove. Moreover, a welding machine (type: TransPuls Synergic CMT 5000, produced by Fronius Company) was utilized, and a mixture of $82 \% \mathrm{Ar}+18 \% \mathrm{CO}_{2}$ was selected. The chemical compositions of the base material Q690 and the wire were shown in Table 1.

\subsection{The Test Method}

2.2.1. Hardness Analysis. Microhardness test was conducted through a nanoindentation measuring device (type: HVS 1000). The test force was $1 \mathrm{Kgf}$ and the force duration was $10 \mathrm{~s}$. The distance between each point was $0.5 \mathrm{~mm}$. The connection between hardness value and microstructure is very close. The hardness is very important in mechanical properties of the materials.

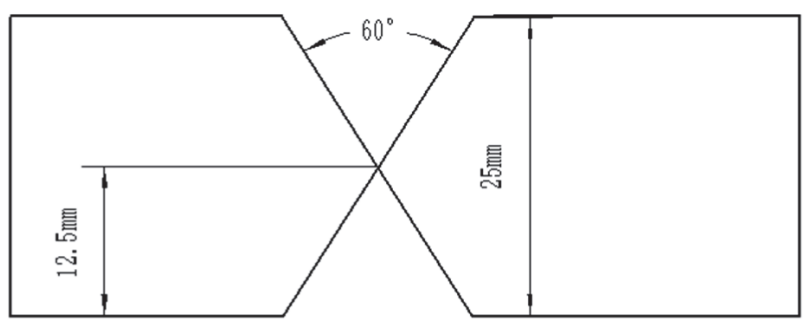

FIGURE 1: Schematic illustration of welded groove.

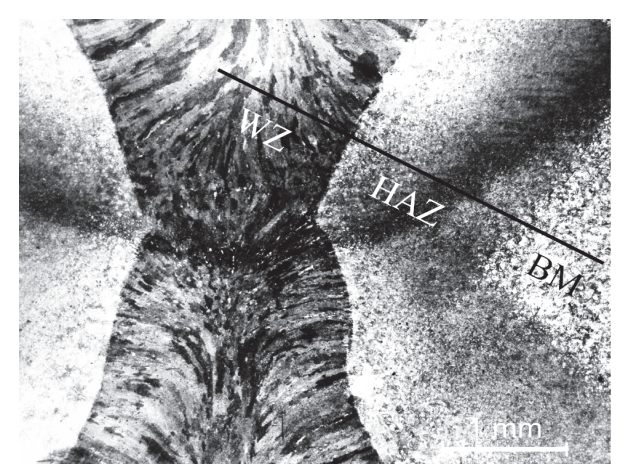

FIgURE 2: Cross section macro-images of the weld joint.

2.2.2. Microstructure Analysis. The micro-images of cross section were shown in Figure 2, which exhibited that joint had good welding quality. Microstructure samples were machined with $10 \mathrm{~mm} \times 10 \mathrm{~mm} \times 5 \mathrm{~mm}$, which ensured that the specimen contained base metal (BM), heat affected zone (HAZ), and weld zone (WZ). Prior to microstructure testing, the sample was polished sequentially with the number of 120, 240, 400, 600,800 , and 1000 emery papers and then polished to the mirror with $1.5 \mathrm{~mm}$ diamond paste. After drying, the specimen was etched by a mixture of $4 \%$ nitric acid and ethanol (weight fraction). The sample was dried with air compressor; microstructure of the sample was observed with metalloscope.

2.2.3. Corrosion Behavior Analysis. All sides of the specimen were embedded in an epoxy resin except the exposure surface, and the working area was $14 \mathrm{~mm} \times 14 \mathrm{~mm}$. Polish the face of the specimen, clean the surface with anhydrous ethanol, and dry it with air compressor. Subsequently, the SVET measurements were conducted through a PAR370 Scanning Electrochemical Workstation. The SVET test was adopted by the Versa SCAN electrochemical scanning system, and the scanning microprobe was a Pt-Ir microelectrode with a 
diameter of $50 \mathrm{um}$. At the beginning of the test, the sample was placed in the electrolytic cell, and the surface of the sample remained horizontal.

The scanning probe vibrated in the perpendicular direction at the surface of the sample, and the distance between the probe and sample surface was $100 \mathrm{um}$. The vibrating amplitude of the microelectrode was $30 \mathrm{um}$ and the vibrating frequency was $50 \mathrm{~Hz}$ in the direction to the surface. The scanning area was $5 \mathrm{~mm} \times 3 \mathrm{~mm}$, and it scanned from weld zone to base metal.

SVET measurements were carried out in electrochemical corrosion testing apparatus at room temperature in 3.5wt\% $\mathrm{NaCl}$ solution [19-21]. And the probe was immersed into 3.5 wt $\% \mathrm{NaCl}$ aqueous solution. The results of SVET were the ion potential difference of local oxidation-reduction reaction on the specimen surface, and the data were converted to local current density according to the specification of data processing in instrument.

The SVET current density maps and the statistical analysis of the data were performed with Origin software. The current densities were displayed in three-dimensional (3D) maps, showing the spatial distribution of the current density as a function of the $(\mathrm{x}, \mathrm{y})$ position in the scan region. The current values in the SVET map are positive for anodic currents and negative for cathodic currents. The contour map of the current densities is at the bottom of the $3 \mathrm{D}$ maps.

The integrated anodic current $\left(\mathrm{I}_{\mathrm{Int}}\right)$ was used to characterize the corrosion resistance of different microstructure. $\mathrm{I}_{\text {Int }}$ was evaluated by integration of the overall anodic current $\left(i_{A}\right)$ on SVET current density map. The whole scan area was split into $21 \times 21$ small squares, and we calculated the scan area (S) and number (n) of measurement points in each microstructure. The scan area of WZ, overheated zone (OZ), normalized zone (NZ), incomplete normalized zone (INZ), and $B M$, respectively, was $4.9,2.2,2.5,0.4$, and $5.0 \mathrm{~mm}^{2}$, and $\mathrm{n}$ of WZ, OZ, NZ, INZ, and BM, respectively, was 142, 56, 74,20 , and 149 . We calculated the anodic current on each microstructure, and calculation formula is shown by

$$
I_{\text {int }}=\frac{S \sum_{\text {iA }}}{n}
$$

(see [22]) where $i_{A}$ is the anodic current density $\left(i_{A}>0\right)$ measurement points in each microstructure.

\section{Result and Discussion}

3.1. The Hardness of the CMT Twin Welded Joint. The distribution of hardness in welded joint is shown in Figure 3. It can be shown that the hardness values of the welded joint are symmetric distribution as a centre of the welded zone. It can be concluded that the welded joint shows relatively uniform fluctuations of hardness in BM, and the value is maintained at about $275 \mathrm{HV}$. In the vicinity of the heat affected zone, the hardness of BM decreases to a certain extent, which is due to the growth of grain on the edge of the HAZ.

The hardness of the HAZ in Figure 3 rises relatively fast, where the troostite has a high hardness (about $310 \sim 332 \mathrm{HV}$ ). Simultaneously, the decrease of troostite near the WZ leads to

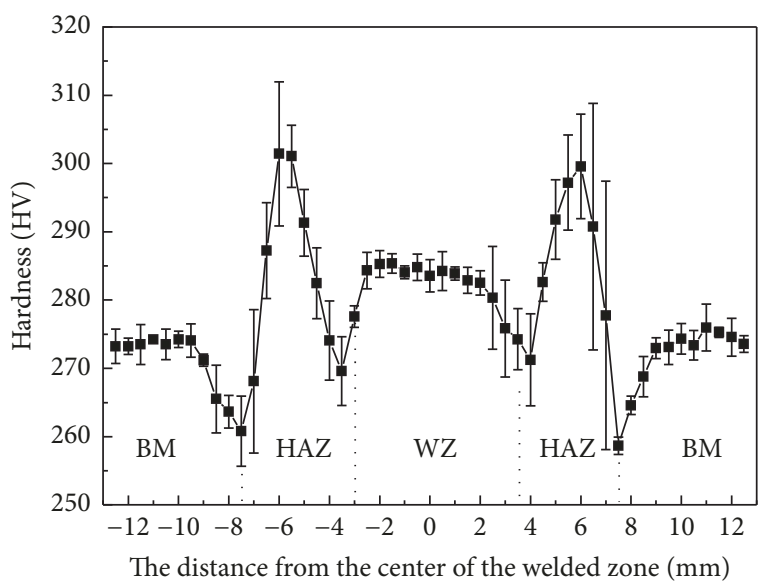

Figure 3: The distribution of the hardness in the welded joint.

further decrease of the hardness on the edge of the HAZ. And the amplitude of descent in hardness is little lower than that of the BM, as presented in Figure 3. It can be shown in Figure 3 that the welded joint shows obvious hardness fluctuation in $\mathrm{HAZ}$, which reveals the inhomogeneous microstructure of $\mathrm{HAZ}$. This leads to heavy corrosion for $\mathrm{HAZ}$ in $3.5 \% \mathrm{NaCl}$ solution. However, the hardness of the HAZ is determined by the tendency of brittleness in the BM and the cooling speed of the HAZ. This means that the brittleness and hardness of the $\mathrm{BM}$ are determined by the chemical composition, while the cooling rate of the HAZ is mainly affected by the welding specification. Generally, the chemical composition of the BM is certain, and the hardness of the HAZ can only be improved by changing the cooling rate after welding. It can be confirmed that the microstructure of the $\mathrm{WZ}$ consists of the bainite and a small amount of acicular ferrite, and the hardness is kept at $285 \mathrm{HV}$, slightly higher than that of the BM.

3.2. Microstructure of the Welded Joint. It can be shown in Figure 4(a) that the microstructure of BM consists of a mixture of ferrite with low carbon slabs and carbide. Meanwhile, the same size of the bainite is parallel with arrangement in direction, which formed the bainite-rich region. The microstructure of lower bainite (LB) is mostly featured with the lath ferrite $(F)$, and from the austenite grain boundary to the intragranular one the parallel growth of ferrite is shown. Simultaneously, the short rod-like black product with intermittent is cementite, which exists in lath ferrite. Moreover, it can be shown in Figure 4 that the welded joint shows obvious crystal boundary of austenite in BM, and the distribution of ferrite is very homogeneous. Specifically, the grain orientation in the region is larger, and plenty of bainite regions are formed.

Figure 4(b) shows optical micrographs of the cross section of the different welding regions (incomplete normalized zone (INZ) and NZ) of the welded joint. It can be shown that the troostite (black substance) is precipitated out of the coarse bainite in HAZ, and it gradually diffuses into the BM. It obviously detects the diffusion process of the troostite in 


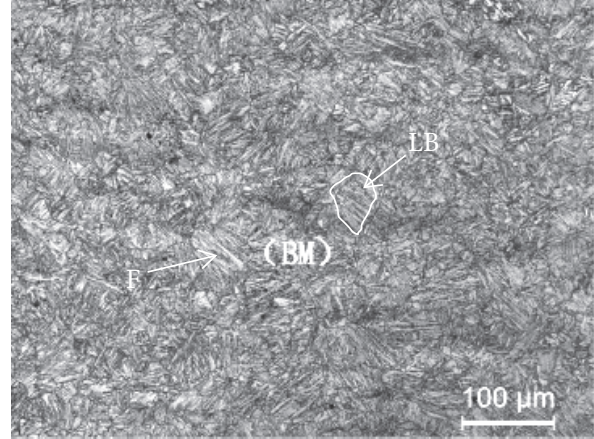

(a)

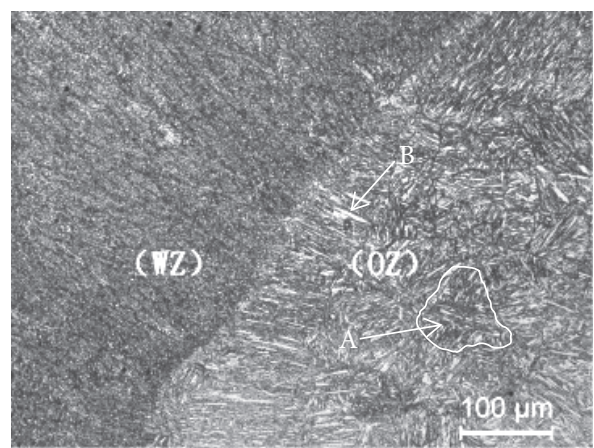

(c)

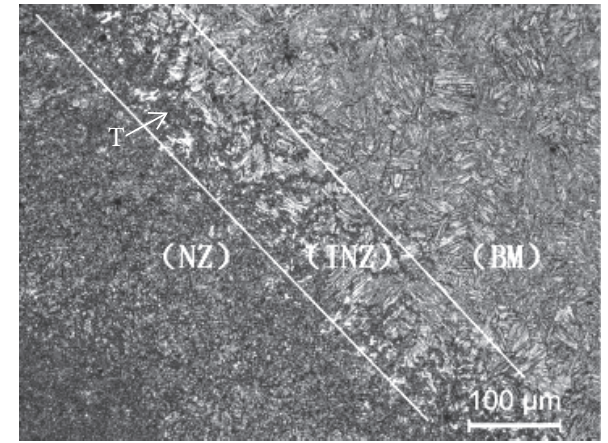

(b)

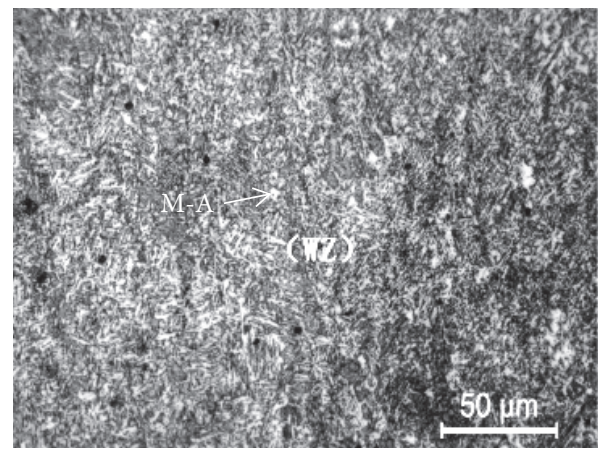

(d)

FIgURE 4: The microstructure of BM, INZ, NZ, OZ, and WZ.

INZ, while NZ is completely covered by the troostite (T). This means that this zone has high mechanical properties (hardness and strength).

Figure 4(c) shows the microstructure of OZ, in which the upper left corner is WZ. It can be seen that the microstructure adjacent to $\mathrm{WZ}$ is relatively coarse and the grain boundary is clear. Moreover, the microstructure adjacent to the fusion line shows that the microstructure of the welded zone is relatively finer compared with the BM, and there also exists black granular troostite in the grain boundary of austenite (A). In the area of BM adjacent to WZ, it can be clearly shown that the microstructure of the BM is basically perpendicular to the fusion line, and bainite (B) becomes longer. In HAZ, the grain boundary of austenite is obvious, and the microstructure of $\mathrm{HAZ}$ is obviously more coarse than that of BM, as presented in Figure 4. Owing to the lower heat input and high speed of cooling after welding, massive bainite with a high density dislocation is formed with dispersive distribution of carbide. The appearance of bainite presents a thin strip and a series of slabs are arranged in parallel. As a result, the same direction bainite grows to form a regional strip, and the slabs of the bainite intersect each other.

Figure 4(d) presents the microstructure of WZ; it can be shown in Figure 4(c) that the microstructure is finer. After magnification, the granular bainite (M-A constituent) is distributed homogeneously. It is well known that the cooling rate greatly affected the formation of granular bainite. The cooling rate influences the growth of factors such as the generation of a significantly quenched hardening structure. Moreover, the low cooling rate increases the austenitic isothermal time, which is favorable for the short-range diffusion of carbon atoms. The quantity of the carbon concentrated in the primary austenite will be suppressed, being affected by the welding heat input, when the bainite ferrite is generated during the bainite transformation. The bainite ferrite formation is prevented by the primary austenite, while the carbon concentration reached a critical value. Therefore, the residual austenite transforms into the M-A island that is distributed within the ferrite matrix. Subsequently, the lath and granular bainite microstructures are generated. Therefore, a large number of small M-A islands are distributed evenly in ferrite matrix. In the process of granular bainite formation, ferrite with precipitating out of austenite firstly is featured with the shape of lath. Meanwhile, lath ferrite with high dislocation density leads to high strength of materials. Owing to the hard phase of $\mathrm{M}-\mathrm{A}$ islands, the $\mathrm{M}-\mathrm{A}$ islands are precipitated by way of small and dispersed precipitation. Indeed, the interaction between M-A islands and the dislocation hinders the dislocation movement. In other words, the way of dispersion strengthening improves the strength of the steel.

3.3. Corrosion Behavior of the CMT Twin Welded Joint. The corrosion of low carbon alloy steel in $3.5 \% \mathrm{NaCl}$ solution is typical electrochemical corrosion. When low carbon alloy steel is immersed in $3.5 \% \mathrm{NaCl}$ solution, the distribution of components, phase, and the surface stress of surface in material are not uniform. Indeed, the distribution of electrode potential between material surface and interface 
of water is inhomogeneous on the microscale. There are countless corrosion microcells on the surface of the metal, resulting in the corresponding anode and cathode areas. The anode is an active dissolving reaction, namely, $\mathrm{Fe}-2 \mathrm{e}=\mathrm{Fe}^{2+}$. In the meantime, the corrosive particles in the environment are mainly $\mathrm{O}_{2}$ and $\mathrm{Cl}^{-}$, in which the concentration of oxygen is consistent, and the cathode is the depolarization reaction of oxygen, namely, $\mathrm{O}_{2}+2 \mathrm{H}_{2} \mathrm{O}+4 \mathrm{e}=4 \mathrm{OH}^{-}$. Therefore, the corrosion rate of the materials may be accelerated by influencing the adsorption behavior of the corrosive $\mathrm{Cl}^{-}$. Furthermore, $\mathrm{Cl}^{-}$is a characteristic adsorption ion, which is able to form a chemical bond of coordination with metal and adsorb on the surface of the metal. This effect usually causes the change of charge on the metal surface.

3.4. SVET Current Density Maps. The SVET current density maps for various periods in $3.5 \% \mathrm{NaCl}$ solution are demonstrated in Figure 5. Simultaneously, the boundary lines of different microstructure were displayed in $\mathrm{X}$ axis. The anodic current appeared at different sites, and the anodic area is mainly located at the BM in 0 hour (Figure 5(a)). The 0 hour is the time for SVET to scan the once.

At the beginning of time $(0 \mathrm{~h})$, the corrosion resistance of the BM and HAZ is worse. In addition, due to the influence of the heat input during the process of welding, there is obvious differentiation of microstructure between BM and WZ. There is obvious potential difference between the $\mathrm{WZ}$ and $\mathrm{BM}$, resulting in galvanic corrosion. Following this, the cathode region appears in the $\mathrm{WZ}$ and thus is protected. In the meantime, the microstructure in the HAZ is relatively coarse. As a result, the corrosion resistance of the $\mathrm{WZ}$ is better than $\mathrm{BM}$. The microstructure of WZ consists of the granular bainite (M-A constituent), as presented in Figure 4. Granular bainite consists of a mixture of ferrite and austenite, and ferrite is surrounded by austenite. In addition, phase transition temperature of bainite is low, and the diffusion ability of alloy elements is relatively worse. Therefore, the uniform bainite reduces the potential difference between the anode and cathode. Thus, it is indicated that the corrosion rate reduces to some extent, especially the tendency of localized corrosion. In addition, grain boundary of bainite is small angle grain boundary, and interfacial energy can be lower, and the impurity content of grain boundary is low, making it shows excellent corrosion resistance.

It has been established that, with the increase of time (2 $\mathrm{h}$ ), the SVET current density in anode region and cathode region decreases. In the initial period of corrosion, the unstable product $\mathrm{Fe}(\mathrm{OH})_{2}$ is formed on the surface of the sample, which to some extent inhibits the process of anodic dissolution of the corrosion reaction, thus reducing the corrosion rate [23]. The anodic current density peak appears in $\mathrm{BM}$, and the area of higher anode current significantly reduces. In the meantime, the cathodic area appears in the HAZ, and the number significantly increases. When time is $4 \mathrm{~h}$, the anodic current density peak appears in WZ. In other words, the anode area is moved from BM to the WZ. Owing to the porous structure of the new rust layer, the rust layer cannot provide adequate protection, so the rust layer on the sample surface is continuously increasing, as shown in Figures 5(b)-5(d). When the corrosion time is $6 \mathrm{~h}$, the peak current area and quantity of the anode decrease gradually. Thus, it means that the corrosion rate of the whole regional greatly reduces, and there are only scattered anode current peaks at the edge of the weld zone. The cathode region appears in HAZ and the BM, which improves the corrosion resistance of the two regions.

3.5. Current Peak of Anodic and Cathodic. It is possible to go further and attempt to extract more information from the SVET results. As shown in Figure 6, it can be observed that the welded joint exhibits the current peak of anodic $\left(i_{A, \max }\right)$, cathodic $\left(\mathrm{i}_{\mathrm{C}, \max }\right)$, and the average current density $\left(\mathrm{i}_{\text {Ave }}\right)$ in SVET maps. It can be seen from the graph that the peak of cathode current and anode current are decreasing gradually, while the average current is moving around zero. The test of corrosion was conducted without external polarization, so the anodic currents and cathodic currents are balanced and the net current should be zero. In general, the current peak of cathode and anode should be equal in value, and the average current density should be zero. However, the difference between the anode and cathode current peaks in SVET maps results in an average current deviation of zero. The reason for this deviation may be that the current density of the SVET maps is not measured at the same time. In the process of scanning, corrosion behavior and current distribution are constantly changing. As shown in Figures $5(\mathrm{a})-5(\mathrm{~d})$, the current density of different microstructure varies considerably with the increase of corrosion time. This shows that the process of electrochemical is instantaneous, which changes at any time.

3.6. Corrosion Behavior of Different Zone. Integrated anodic current of different microstructure is as shown in Figure 7. It shows that the integrated anodic current $\left(\mathrm{I}_{\text {Int }}\right)$ of $\mathrm{OZ}$ and $\mathrm{BM}$ is larger than that of $\mathrm{WZ}$ in the whole corrosion process. Combined with SVET maps, the corrosion tendency of microstructure in $\mathrm{WZ}$ is relatively high and the corrosion rate is low. At the same time, the degree of corrosion in $\mathrm{WZ}$ is lower than that of BM. As the iron dissolves, the integrated anodic current in BM and $\mathrm{OZ}$ decreases gradually. Moreover, the corrosion products decrease the corrosion rate of $\mathrm{WZ}$ and $\mathrm{BM}$. Due to the coarse microstructure in $\mathrm{HAZ}$, the integrated anodic current increases (0-2 h). With the oxidation of $\mathrm{Fe}(\mathrm{OH})_{2}$, the integrated anodic current of BM and $\mathrm{OZ}$ increases slightly $(2-4 \mathrm{~h})$. As the size of microstructure varies, $\mathrm{I}_{\text {Int }}$ in the $\mathrm{BM}$ decreases, while $\mathrm{I}_{\text {Int }}$ in $\mathrm{OZ}$ is relatively stable $(4-6 \mathrm{~h})$. Generally, the size of the integrated anodic current reflects the corrosion rate of different regions. With the formation of corrosion products, the corrosion rate of NZ gradually decreases (2-6 h). The weld zone is protected by the cathode and the degree of corrosion is little. Compared with the NZ, the corrosion resistance of the INZ is enhanced, which is due to the decrease of the amount of the troostite. 


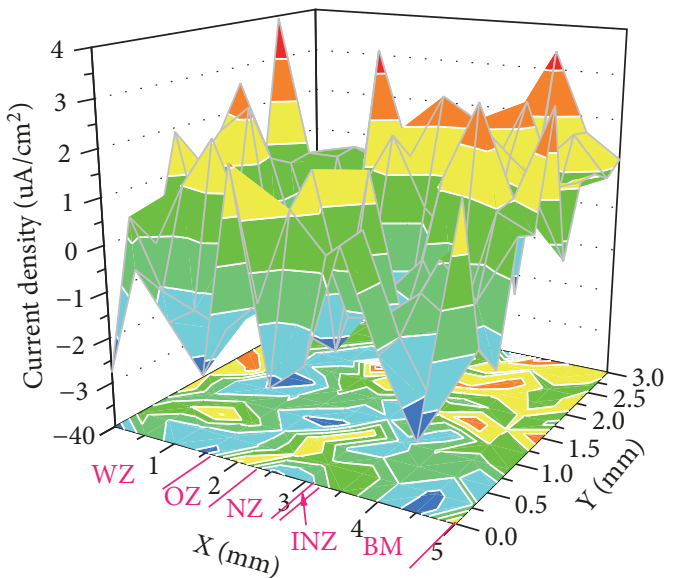

(a)

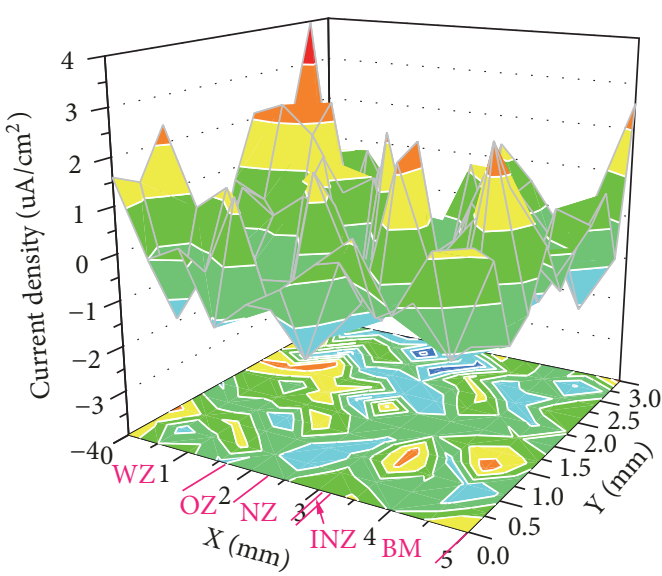

(c)

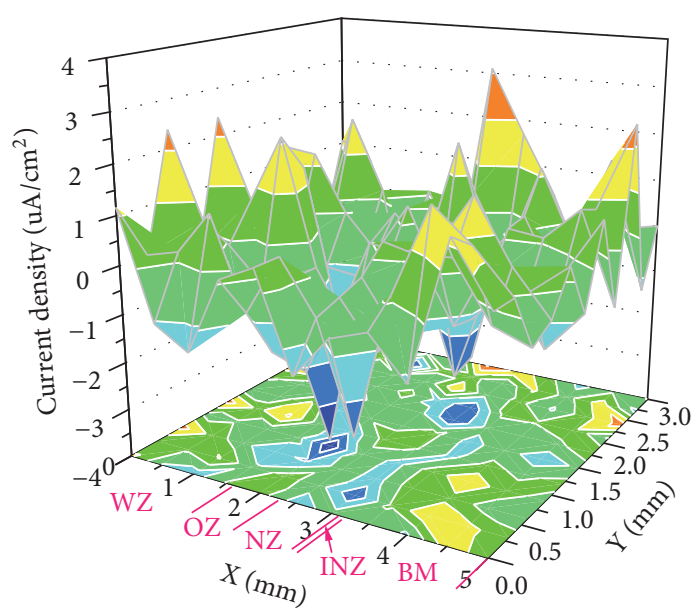

(b)

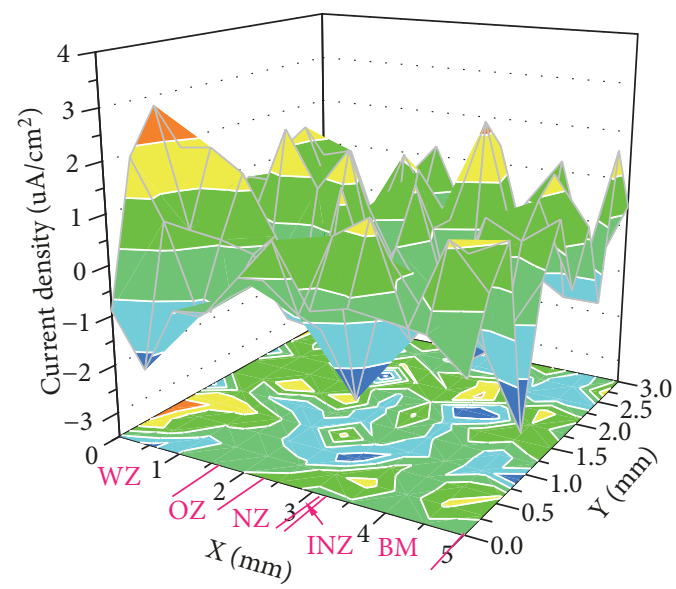

(d)

FigURE 5: SVET current density maps of (a) $0 \mathrm{~h}$, (b) $2 \mathrm{~h}$, (c) $4 \mathrm{~h}$, and (d) $6 \mathrm{~h}$.

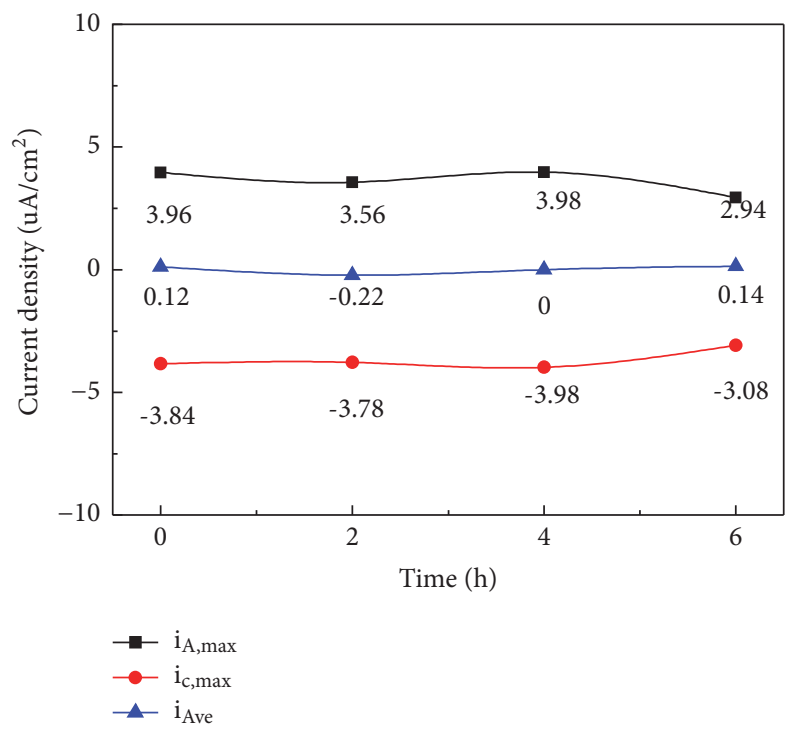

FIgURE 6: The current peak of anodic $\left(\mathrm{i}_{\mathrm{A}, \max }\right)$, cathodic $\left(\mathrm{i}_{\mathrm{C}, \max }\right)$, and the average current density $\left(\mathrm{i}_{\text {Ave }}\right)$ in SVET maps.

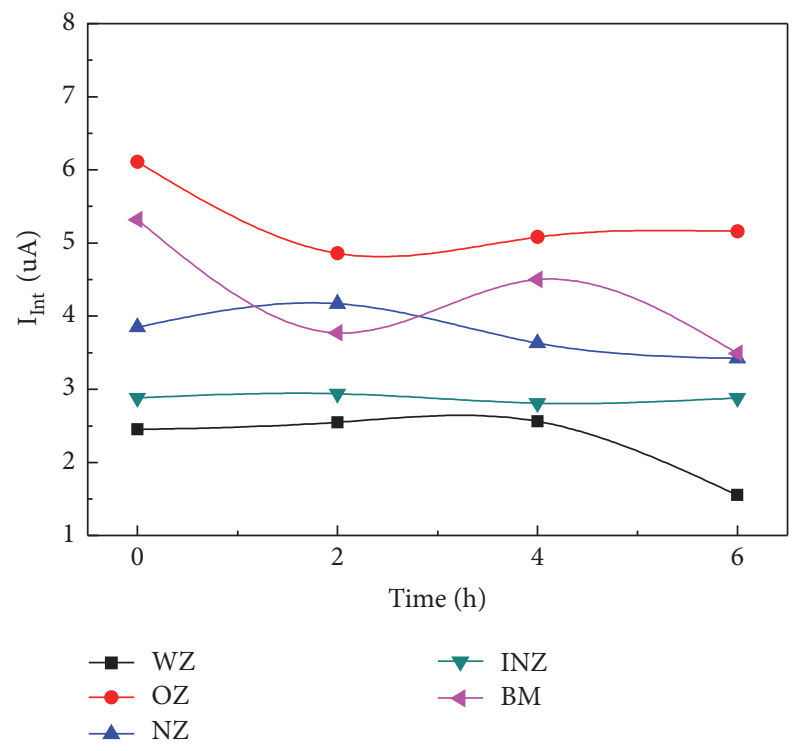

FIGURE 7: Integrated cathodic current $\left(\mathrm{I}_{\text {Int }}\right)$ of different microstructure. 


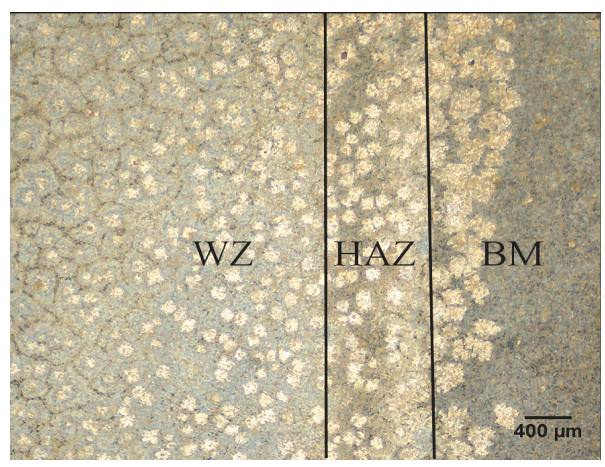

(a)

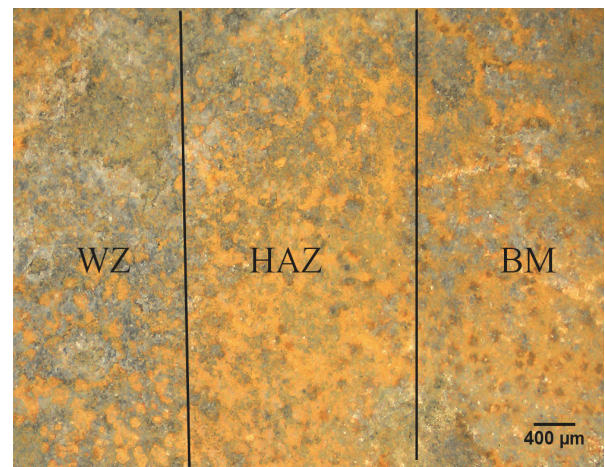

(c)

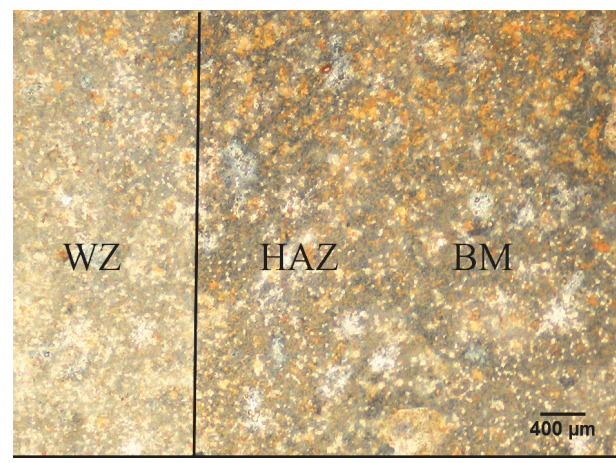

(b)

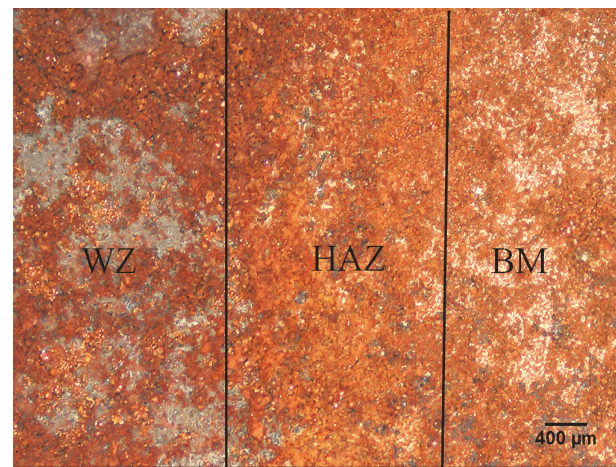

(d)

Figure 8: The macroscopic appearance of different corrosion time.

3.7. Macro Analysis of Welded Joint after Corrosion. The macroscopic appearance of different corrosion times in welded joint is demonstrated in Figure 8. Figure 8(a) reveals that different degrees of corrosion occurred in the BM, WZ, and HAZ. That is to say, the results are in agreement with the distribution of current density maps (Figure 5(a)). The white corrosion products, including $\mathrm{Fe}(\mathrm{OH})_{2}$, are mainly distributed in the HAZ and the zone adjacent to the HAZ (BM and $\mathrm{WZ}$ ). In the $\mathrm{WZ}$, the white corrosion products, which are away from the area of HAZ, gradually decrease. Moreover, on the right of Figure 8(a), the coarse microstructure of HAZ leads to lesser corrosion product.

When corrosion time is $2 \mathrm{~h}$, white corrosion products disappeared, and a few corrosion products $\left(\mathrm{Fe}(\mathrm{OH})_{2}\right)$ with rufous appear. Furthermore, it is apparent that the boundary of the HAZ and the BM basically disappeared. That is to say, the corrosion products of the BM and the HAZ are obviously more than the WZ. It is revealed that $\mathrm{Fe}(\mathrm{OH})_{2}$ is easily oxidized to products of gray-green. The products of rufous are mainly concentrated in the HAZ, and the BM has fewer corrosion products and the least ones in WZ, as presented in Figure 8(c). When corrosion time is $6 \mathrm{~h}$, there are obvious differences in WZ, HAZ, and BM. Figure 8(d) shows the corrosion degree of $\mathrm{WZ}$ is the minimum, and the corrosion resistance is excellent. Furthermore, the corrosion products in BM have not been completely oxidized, and some corrosion products of white $\left(\mathrm{Fe}(\mathrm{OH})_{2}\right)$ exist.

As Figure 8 shows, the corrosion degree of each region is not uniform at any time. The grains of granular bainite in
WZ are finer and evenly distributed, and the distribution of microstructure is uniform. It is well known that the content of granular bainite is high in Q690. In addition, the small cathode and large anode lead to reducing the corrosion rate of $\mathrm{WZ}$ in the process of corrosion. As shown in Figure 8, the $\mathrm{WZ}$ displays the excellent corrosion resistance. On the contrary, the HAZ with coarse microstructure exhibits the worst corrosion resistance. It may also be that nickel increases the corrosion resistance of the weld area. As shown in Table 1, there are more nickel elements in the weld zone, in comparison with BM. The study shows that the addition of nickel can form a protective rust layer on the surface, thus improving the corrosion resistance of the welded zone [24]. Ni has ability to resist the corrosive action of $\mathrm{Cl}^{-}$ions. Accordingly, $\mathrm{Ni}$ exhibits high corrosion resistance in $3.5 \% \mathrm{NaCl}$ solution. This indicates that, as a result of $\mathrm{Ni}$ in the welded zone, the aggressive action of $\mathrm{Cl}^{-}$ions on the surface is suppressed. This behavior exhibits very important result that the Ni has influence on corrosion resistance in $3.5 \% \mathrm{NaCl}$ solution.

In summary, it can be discovered that the corrosion rates of various zone are associated with the welding heat input. From this perspective, the corrosion degree of microstructure is mainly $\mathrm{HAZ}>\mathrm{BM}>\mathrm{WZ}$.

\section{Conclusions}

The microstructure, hardness, and corrosion behavior in welded joint of Q690, which was welded with CMT Twin, 
were studied. The experimental findings support the following major conclusions:

(1) The hardness of the base metal was the minimum, while the hardness of weld zone with tiny microstructure was higher than that of the base metal. Owing to the coarse microstructure, the hardness of overheated zone decreased. The hardness of normalized zone increased with the appearance of the troostite.

(2) As the corrosion time increases, the corrosion products of different microstructure were identical, and the white products of the welded joint were turned into products of rufous. In the role of oxygen, $\mathrm{Fe}(\mathrm{OH})_{2}$ was oxidized to $\mathrm{Fe}(\mathrm{OH})_{3}$. Also, the overheated zone and the base metal presented a high corrosion rate. The degree of corrosion in weld zone, which is protected by the cathode, was mild. The corrosion resistance of the weld zone with CMT Twin was greatly improved compared with that of the base metal. This was related to the existence of nickel.

\section{Data Availability}

The data used to support the findings of this study are available from the corresponding author upon request.

\section{Conflicts of Interest}

The authors declare that there are no conflicts of interest regarding the publication of this paper.

\section{Acknowledgments}

This research was finished with the fund of Science and Technology Project of Guangdong Province (2017A010106007, 2017A010102008, and 201101C0104901263) and Science and Technology Project of Guangzhou (201508030023). The authors are grateful to Guangdong Welding Institute (ChinaUkraine E. O. Paton Institute of Welding).

\section{References}

[1] Z. S. Li, S. L. Li, X. H. Zhang, and J. Z. Liu, "Interaction study of carbide precipitation and impurity segregation under temper embrittlement conditions in a coarse-grained heataffected zone in Q690 steel," Advanced Materials Research, vol. 1015, pp. 189-193, 2014.

[2] X. Chen and Y. Huang, "Hot deformation behavior of HSLA steel Q690 and phase transformation during compression," Journal of Alloys and Compounds, vol. 619, pp. 564-571, 2015.

[3] H. Wan, C. Du, Z. Liu, D. Song, and X. Li, "The effect of hydrogen on stress corrosion behavior of X65 steel welded joint in simulated deep sea environment," Ocean Engineering, vol. 114, pp. 216-223, 2016.

[4] R. Pérez-Mora, T. Palin-Luc, C. Bathias, and P. C. Paris, "Very high cycle fatigue of a high strength steel under sea water corrosion: A strong corrosion and mechanical damage coupling," International Journal of Fatigue, vol. 74, pp. 156-165, 2015.

[5] Y. Ye, C. Wang, H. Chen, Y. Wang, J. Li, and F. Ma, "An analysis of the tribological mechanism of GLC film in artificial seawater," RSC Advances, vol. 6, no. 39, pp. 32922-32931, 2016.
[6] F. Gan, G. Tian, Z. Wan, J. Liao, and W. Li, "Investigation of pitting corrosion monitoring using field signature method," Measurement, vol. 82, pp. 46-54, 2016.

[7] V. Verdingovas, M. S. Jellesen, and R. Ambat, "Colorimetric visualization of tin corrosion: A method for early stage corrosion detection on printed circuit boards," Microelectronics Reliability, vol. 73, pp. 158-166, 2017.

[8] D. Mata, M. Serdechnova, M. Mohedano et al., "Hierarchically organized Li-Al-LDH nano-flakes: A low-temperature approach to seal porous anodic oxide on aluminum alloys," RSC Advances, vol. 7, no. 56, pp. 35357-35367, 2017.

[9] A. C. Bastos, M. C. Quevedo, O. V. Karavai, and M. G. Ferreira, "Review—on the application of the scanning vibrating electrode technique (svet) to corrosion research," Journal of The Electrochemical Society, vol. 164, no. 14, pp. C973-C990, 2017.

[10] V. I. Danilov, L. B. Zuev, S. V. Konovalov et al., "On the effect of electric potential on resistance of metals surface to microindentation," Journal of Surface Investigation X-ray Synchrotron and Neutron Techniques, vol. 1, pp. 157-161, 2010.

[11] S. A. Nevskii, S. V. Konovalov, and V. E. Gromov, "Effect of the electric potential of the aluminum surface on stress relaxation," Technical Physics, vol. 56, no. 6, pp. 877-880, 2011.

[12] M. G. Taryba and S. V. Lamaka, "Plasticizer-free solid-contact $\mathrm{pH}$-selective microelectrode for visualization of local corrosion," Journal of Electroanalytical Chemistry, vol. 725, pp. 32-38, 2014.

[13] A. S. Gnedenkov, S. L. Sinebryukhov, D. V. Mashtalyar, and S. V. Gnedenkov, "Localized corrosion of the Mg alloys with inhibitor-containing coatings: SVET and SIET studies," Corrosion Science, vol. 102, pp. 269-278, 2016.

[14] L. W. Wang, Z. Y. Liu, Z. Y. Cui, C. W. Du, X. H. Wang, and X. G. Li, "In situ corrosion characterization of simulated weld heat affected zone on api x80 pipeline steel," Corrosion Science, vol. 85, pp. 401-410, 2014.

[15] W. Liu, H. Pan, L. Li et al., "Corrosion behavior of the high strength low alloy steel joined by vertical electro-gas welding and submerged arc welding methods," Journal of Manufacturing Processes, vol. 25, pp. 418-425, 2017.

[16] N. Fuertes, V. Bengtsson, R. Pettersson, and M. Rohwerder, "Use of SVET to evaluate corrosion resistance of heat tinted stainless steel welds and effect of post-weld cleaning," Materials and Corrosion, vol. 68, no. 1, pp. 7-19, 2017.

[17] L. Luo, Y. Huang, and F.-Z. Xuan, "Deflection behaviour of corrosion crack growth in the heat affected zone of $\mathrm{CrNiMoV}$ steel welded joint," Corrosion Science, vol. 121, pp. 11-21, 2017.

[18] H. Ma, Y. Gu, H. Gao, X. Jiao, J. Che, and Q. Zeng, "Microstructure, chemical composition and local corrosion behavior of a friction stud welding joint," Journal of Materials Engineering \& Performance, vol. 2, pp. 666-676, 2018.

[19] B. Yan, H. Chen, and D. Kong, "Effects of laser remelting on salt spray corrosion behaviors of arc-sprayed Al coatings in 3.5\% $\mathrm{NaCl}$ sea environment," Transactions of the Indian Institute of Metals, vol. 6, pp. 1-9, 2017.

[20] S. Weng, Y. Huang, F. Xuan, and F. Yang, "Pit evolution around the fusion line of a NiCrMoV steel welded joint caused by galvanic and stress-assisted coupling corrosion," RSC Advances, vol. 8, no. 7, pp. 3399-3409, 2018.

[21] H. S. Gadow, M. M. Motawea, and H. M. Elabbasy, "Investigation of myrrh extract as a new corrosion inhibitor for $\alpha$-brass in $3.5 \% \mathrm{NaCl}$ solution polluted by $16 \mathrm{ppm}$ sulfide," RSC Advances, vol. 7, no. 47, pp. 29883-29898, 2017. 
[22] M. Yan, V. J. Gelling, B. R. Hinderliter, D. Battocchi, D. E. Tallman, and G. P. Bierwagen, "SVET method for characterizing anti-corrosion performance of metal-rich coatings," Corrosion Science, vol. 52, no. 8, pp. 2636-2642, 2010.

[23] Y. Ma, Y. Li, and F. Wang, "The effect of $\beta-\mathrm{FeOOH}$ on the corrosion behavior of low carbon steel exposed in tropic marine environment," Materials Chemistry and Physics, vol. 112, no. 3, pp. 844-852, 2008.

[24] H. M. Abd El-lateef, A. El-Sayed, and H. S. Mohran, "Role of $\mathrm{Ni}$ content in improvement of corrosion resistance of $\mathrm{Zn}-\mathrm{Ni}$ alloy in 3.5\% NaCl solution. Part I: Polarization and impedance studies," Transactions of Nonferrous Metals Society of China, vol. 25, no. 8, pp. 2807-2816, 2015. 


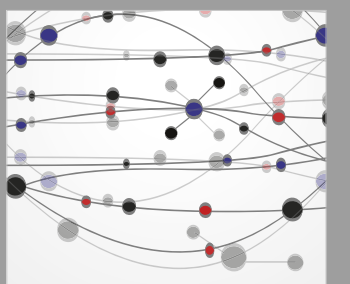

The Scientific World Journal
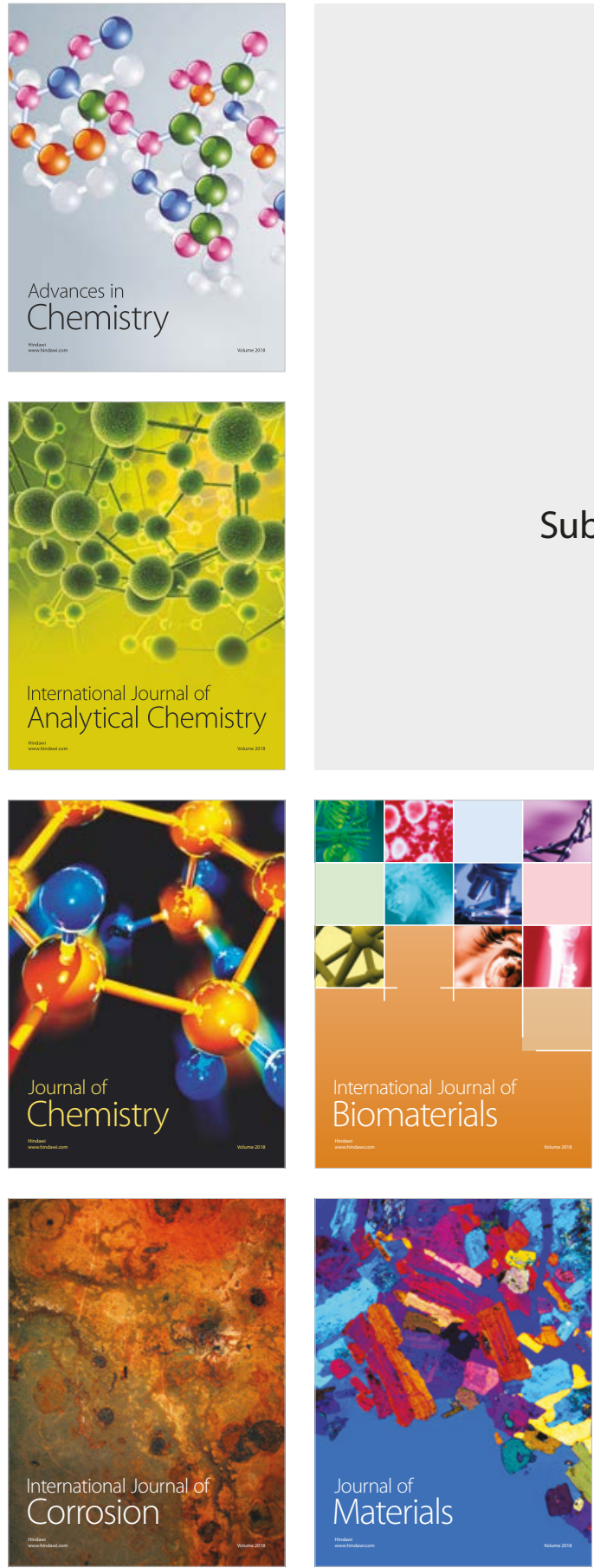

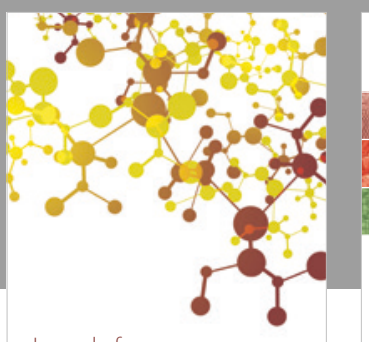

Journal of

Applied Chemistry
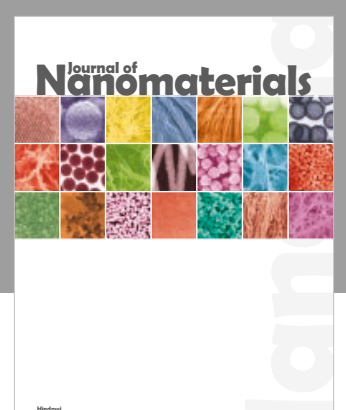

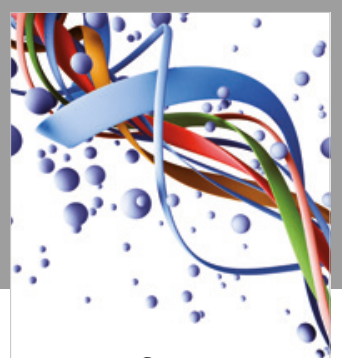

Scientifica

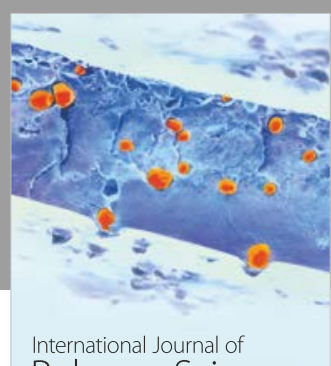

Polymer Science

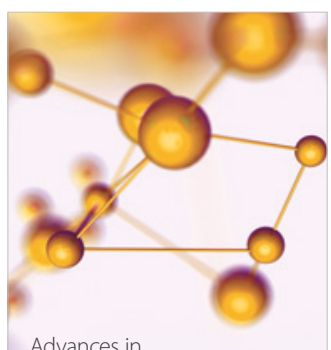

Physical Chemistry
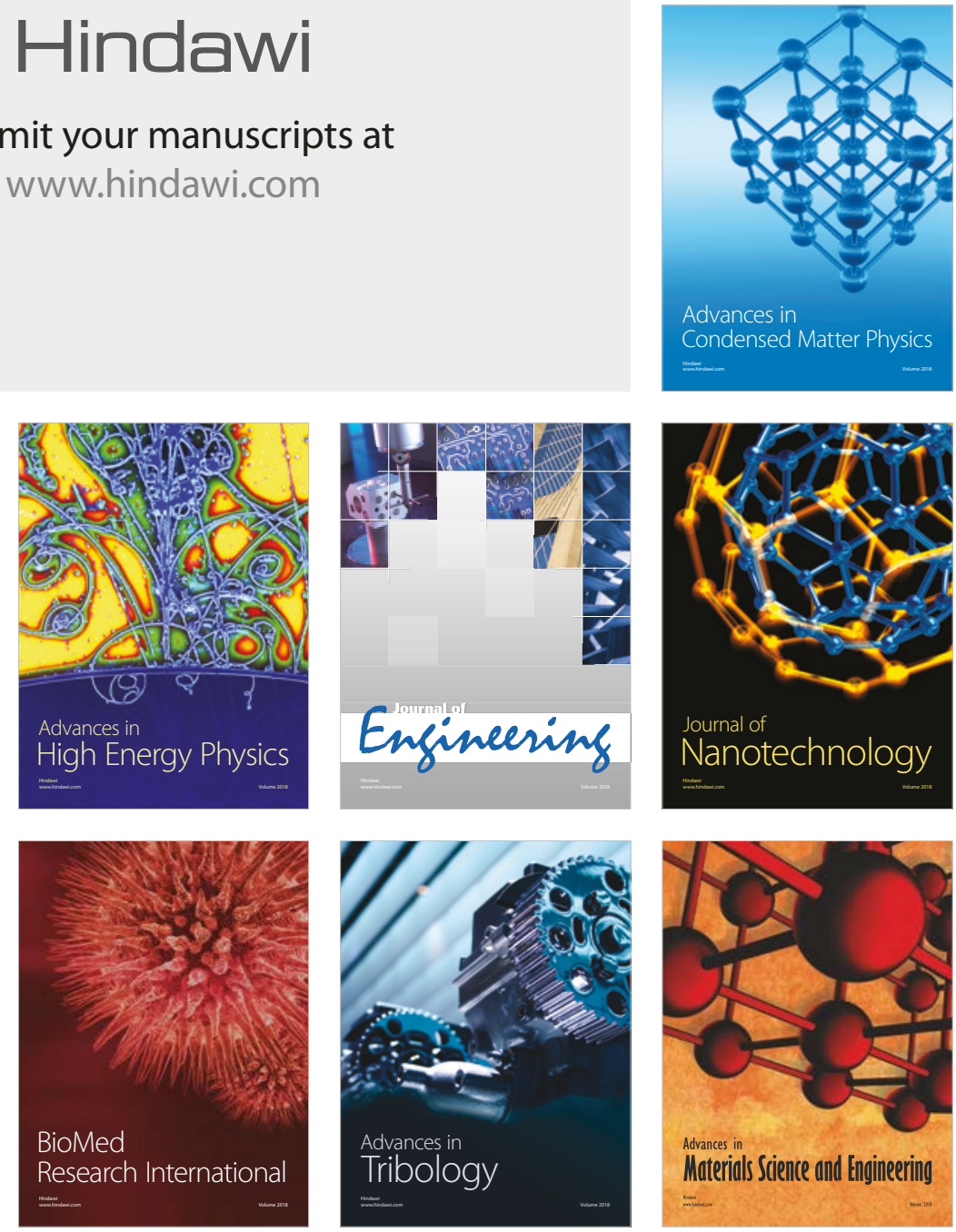